Review

\title{
High-Performance Polymers for Aeronautic Wires Insulation: Current Uses and Future Prospects
}

\section{Gérald Lopez *}

SAFRAN Tech - Materials \& Processes Department, Rue des jeunes bois, Châteaufort CS 80112, 78772 Magny les Hameaux, France; E-Mail: gerald.lopez@safrangroup.com

* Correspondence: Gérald Lopez; E-Mail: gerald.lopez@safrangroup.com

Academic Editor: Hossein Hosseinkhani

Recent Progress in Materials

2021, volume 3 , issue 1

doi:10.21926/rpm.2101005
Received: November 25, 2020

Accepted: February 02, 2021

Published: February 25, 2021

\begin{abstract}
Polymers such as polyimides and fluoropolymers are widely used for insulating aeronautic wires. They are exposed to various changing factors such as temperature, pressure, moisture, vibration, chafing, etc. The electrification on the horizon can potentially increase the demand for these systems. Indeed, this impending evolution of technology pushes the boundaries of commonly-employed wires. Downsizing systems and enhancing the performance is an urgent requirement. A new generation of insulating materials capable of handling higher continuoususe temperature and voltage is required for the efficient running of aircraft. This review aims at providing the polymer community the keys for addressing such a crucial industrial issue.
\end{abstract}

\section{Keywords}

Fluoropolymers; polyimides; insulations; jackets; wires

\section{Introduction}

The demand to reduce gas emissions, optimize aircraft performances, and decrease maintenance costs, has pushed the aircraft industries toward the concept of More Electric Aircraft (MEA) [1].

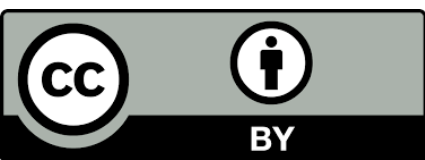


Electric power systems are increasingly supplanting pneumatic, hydraulic, and mechanical power systems. Maintaining the weight of an aircraft within its original specifications is often a challenge, and a gram saved in wiring is a gram that can be used to increase payload and decrease fuel consumption. Higher currents are avoided because of voltage drop and weight. Hence, there is a plan to use higher operating voltages for developing the next generation of wires.

In 1936, electrical systems were operated at 14.25 volts direct current (VDC). The operating voltage was increased to 28 VDC in 1946. Finally, the 115/200 volts alternating current (VAC) and $400 \mathrm{~Hz}$ systems became the conventionally used systems. Aircraft are currently conceived with a more electric architecture [2]. For instance, the Boeing 787 operates under a hybrid voltage system consisting of $235 \mathrm{VAC}, 115 \mathrm{VAC}, 28 \mathrm{VDC}$, and $\pm 270 \mathrm{VDC}$, producing twice as much electricity as those used to operate the previous models [3]. The electric power demand on a B787 is nearly $1 \mathrm{MW}$, which is double that of a B777 [3]. Thus, polymeric insulation materials experience higher electrical stress and are operated under harsh conditions. These result in several technical challenges.

The use of increased voltages leads to a higher risk of electrical discharge events such as gaseous breakdown, electrical arc, and partial discharges [4]. Nowadays, the targeted voltages remain lower than 1000 VDC. However, this level of tension can be potentially increased in the future (according to the International Electrotechnical Commission (IEC 60038), the voltage class is considered as medium voltage (MV) when in the range of 1-45 kV). Hence, the high-tension level can lead to the premature deterioration of the polymeric insulation materials.

Higher temperature electronics are required to achieve downsizing, lower weight, and better efficiency. This impending evolution of the technology engenders an increased concentration of energy and pushes the boundaries of the amperage capacity of the commonly-employed wires. Temperature is a critical influencing factor when it comes to polymer dielectrics [5]. For instance, the volume resistivity, which reflects the electrical insulating ability of the material, decreases as the temperature increases. The dielectric strength is significantly influenced by the temperature: as the temperature increases, the dielectric strength significantly decreases. Mechanical properties such as tensile strength, flexural, and Young's moduli are also influenced by the temperature elevation.

\section{High-Performance Polymers Commonly Used as Insulation Materials in Aeronautic Wires}

\subsection{Polyimides}

The history of polyimide (common trade name Kapton ${ }^{\circledR}$ developed by DuPont in Wilmington DE, Figure 1) as insulation material for wires is unique. Invented in 1955, it was quickly accepted as a great insulating material exhibiting an exceptional combination of thermal stability, mechanical toughness, and chemical resistance. Hence, manufacturers fabricated a tape that was wrapped around a conductor to create an insulated wire. Kapton ${ }^{\circledR}$ made a rapid entry into the fields of commercial and military aircraft (and even space shuttles) in the 1970s. However, the popularity of Kapton ${ }^{\circledR}$ wiring ended in the early 1980s when the US military observed that aircraft fires and crashes could be attributed to electrical short circuits. 


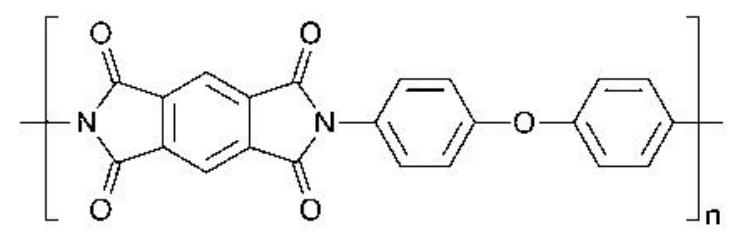

Figure 1 Chemical structure of Kapton ${ }^{\circledR}$.

Polyimide was indeed involved in several incidents with aircraft and became, for a while, the threat of the aerospace industry. Polyimides rapidly degrade when exposed to a combination of heat, humidity, and mechanical strain (Figure 2) [6].

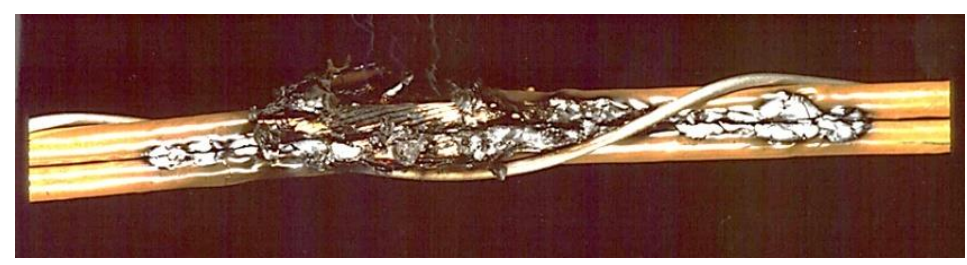

Figure 2 Damaged Kapton ${ }^{\circledR}$ wires.

Some polyimide wires degrade rapidly, leading to electrical arcing events, which leads to the charring of the polymer. According to Armin Bruning, from the Lectromechanical Design Company, Kapton $^{\circledR}$ explodes during an arc tracking event and "flashover" because "the arc will cause a temperature of $5000^{\circ} \mathrm{C}$ and under this condition, carbon is vaporized, and free hydrogen is liberated" [7].

In the early 90s, the Kapton ${ }^{\circledR}$ threat was well-established, and polyimide-based wires began to be feared. The US Navy banned polyimide wires for aircraft applications in 1992. Original equipment manufacturers (OEMs) started looking for alternatives to polyimide insulated wires. They did not want to compromise with the outstanding mechanical performances exhibited by Kapton ${ }^{\circledR}$. To reduce the exposure of the polyimide insulation to water and aeronautical fluids, polyimides were paired with a PTFE Teflon ${ }^{\circledR}$ top layer for constructing wires to reduce the threats posed by arc tracking.

In the late 90s, Airbus started using Kapton ${ }^{\circledR}$ coated with Teflon ${ }^{\circledR}$, known generically as "KT" (standing for Kapton ${ }^{\circledR}$-Teflon ${ }^{\circledR}$ ). However, according to some specialists, this type of wire is "just Kapton ${ }^{\circledR}$ with a cosmetic coating of Teflon which is used for marking purposes only and does little to reduce Kapton ${ }^{\circledR \prime}$ 's propensity to explosively arc track" [7]. A wire, known as "TKT" has been installed in Boeing 757s and 737s that were built after 1992 (Figure 3). As of mid-2006, Airbus is using its version of TKTs. Those are some of the few construction types of wires that can perform well under conditions of high temperatures (up to $260^{\circ} \mathrm{C}$ ).

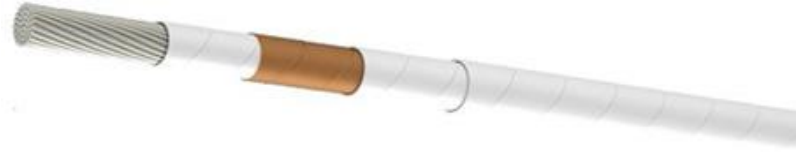

Figure 3 TKT wire. From left to right: Copper core, Teflon $^{\circledR}$, Kapton $^{\circledR}$, Teflon $^{\circledR}$, Teflon $^{\circledR}$ jacket. 


\subsection{Fluoroplastics}

Since the fortuitous finding of polytetrafluoroethylene (PTFE, DuPont-now Chemours-trade name Teflon $^{\circledR}$ ) in 1938, fluorinated polymers have attracted immense attention as highperformance materials. Fluorinated polymers represent a particular class of materials that exhibit excellent properties [8], such as a low coefficient of friction and low surface tension, arising from low intermolecular forces. Indeed, PTFE is free from permanent dipole moment because of the symmetric distribution of the charges (despite the polar nature of the carbon-fluorine bond arising from the high electronegativity of fluorine (Pauling scale 3.98) compared to carbon (2.55)). Fluorinated polymers exhibit excellent chemical, high temperature, and weathering resistance. These properties can be attributed to the stability of the multiple carbon-fluorine bonds. The properties of low dielectric constant, high-temperature stability, low moisture absorption, and low outgassing make fluorinated polymers good candidates for use as insulation materials.

\subsubsection{Polytetrafluoroethylene, PTFE}

PTFE is a versatile plastic fluoropolymer suitable for a wide range of applications [9]. PTFE is insoluble in most solvents and practically chemically inert. It is thermally stable with a continuoususe temperature of approximately $260^{\circ} \mathrm{C}$. Unsintered PTFE exhibits a melting temperature $\left(T_{m}\right)$ of $342{ }^{\circ} \mathrm{C}$ and a degree of crystallinity fluctuating from $89 \%$ to $98 \%$. Post sintering, the $\mathrm{T}_{\mathrm{m}}$ changes to approximately $327^{\circ} \mathrm{C}$, and the degree of crystallinity ranges from $38 \%$ and $53 \%$, depending on the grade of PTFE under study. PTFEs exhibit high flexural strength, electrical resistance, and dielectric strength, water repellency, and low coefficient of friction. PTFE is usually of high molecular weight, which helps achieve satisfactory mechanical properties. Because of its high melt viscosity, the process of manufacturing PTFE parts is different from that employed with typical melt-processable polymers (i.e., injection and extrusion molding). PTFE does not withstand high energy radiation and exhibits poor wear and abrasion resistance [10]. To overcome this problem, various fillers are added to PTFE.

Filler-added PTFE materials. PTFE exhibits a low coefficient of friction $(\mu<0.2$, even under conditions of dry sliding). At sliding speeds above $8 \times 10^{-3} \mathrm{~m} / \mathrm{s}$ at room temperature, it exhibits high wear rates $\left(10^{-3} \mathrm{~mm}^{3} / \mathrm{Nm}\right)[11,12]$ and generates large amounts of plate-like debris [13]. The addition of micro- or nanoscale fillers can potentially result in reduced wear rates of the composites $[14,15]$. The addition of filler can modify features such as abrasion resistance, creep resistance, thermal conductivity, and coefficient of linear expansion [16]. The addition of some fillers turns PTFE black or dark brown (Figure 4) [17].

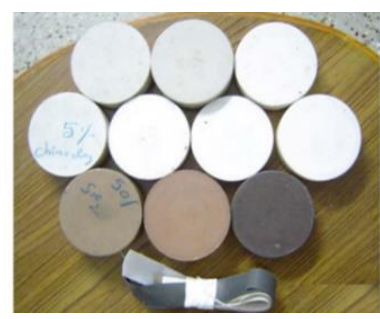

Figure 4 PTFE-filled composites post sintering. Reproduced with permission from literature report [17]. Copyright 2015, IJSRP INC. 
The nature of glass fiber does not exert a significant impact on chemical and electrical properties. However, glass fiber-PTFE composites exhibit approximately twice the compression creep resistance and approximately 1000 times better abrasion resistance than pure PTFE [18]. Amorphous carbon is widely used as PTFE-filler [19]. PTFE-carbon composites exhibit improved creep resistance, hardness, and thermal conductivity. Moreover, PTFE-graphite composites display outstanding wear properties. Carbon-containing PTFE composites exhibit electrical conductivity and are therefore antistatic. Micas are light and flexible soft-sheet silicates. During the processing of PTFE-mica composites, the particles align perpendicular to the pressing direction, resulting in a decrease in shrinkage and thermal expansion. However, the tensile properties remain poor. Quadrant EPP's Fluorosint ${ }^{\circledR}$ PTFE-mica composites exhibit improved load carrying capabilities and a lower coefficient of thermal expansion as compared to PTFE [20]. High loading of bronze filler in PTFE leads to the formation of composites with enhanced thermal conductivity and creep resistance [21]. Bronze tends to oxidize; thus, leading to some discoloration. However, this does not affect the final properties of the materials. However, bronze-filled PTFEs are not appropriate candidates for use in electrical appliances (they are sensitive to chemicals). PTFE-calcium fluoride composites are particularly suitable for applications under conditions of hydrofluoric acid and strong alkalis [22]. Molybdenum disulfide-filled PTFE composites exhibit improved hardness, stiffness, and lower friction. The electrical properties of the PTFEs are not significantly affected [23]. $\mathrm{MoS}_{2}$ is commonly used in low percentages in association with other fillers. Aluminum oxide is an excellent electrical insulator that improves the mechanical properties of PTFE composites and makes them suitable for high voltage applications. Nevertheless, $\mathrm{Al}_{2} \mathrm{O}_{3}$ hardness impairs machining of the sintered parts [24]. Aromatic polyester-based resin-added PTFE exhibits improved mechanical properties such as compression and bending [25]. Polyimides-PTFE composites present a very low coefficient of friction [26]. This makes them suitable candidates for dry running applications. Nevertheless, the cost of operation with this composite is higher than that with all other PTFE composites.

\subsubsection{Ethylene Tetrafluoroethylene, ETFE}

ETFE (ethylene tetrafluoroethylene), commonly referred to as Tefzel ${ }^{\circledR}$, is a copolymer of ethylene (E) and tetrafluoroethylene (TFE). ETFE is often employed in wire insulation for flight hardware. As compared to PTFE, it exhibits enhanced impact strength, abrasion, and cut-through resistance. ETFE is resistant to radiation and exhibits higher mechanical strength than other fluoropolymers. Tefzel ${ }^{\circledR}$ is free from creep issues noticed in incorrectly sintered PTFE. ETFE is processed following the same techniques as those followed to develop other thermoplastics (e.g., heat sealing, thermoforming, laminating, and die-cutting). Based on the $20,000 \mathrm{~h}$ criterion, most grades are rated for continuous use at $150{ }^{\circ} \mathrm{C}$. Corrosion was observed in wires bagged or in a confined area [27]. Carbonyl difluoride, which is released during the manufacturing process, reacts with moisture and leads to the formation of hydrogen fluoride.

ETFE presents the advantage of being cross-linked by high-energy radiation. Cross-linked ETFE, also referred to as XL-ETFE, can be continuously used at $200{ }^{\circ} \mathrm{C}$ and exhibits improved tensile strength and anti-aging resistance. The Marmon Aerospace \& Defense Company supplies hightemperature wires featuring a dual insulation layer of XL-ETFE [28]. Those wires are resistant to fuel and lubricating oils. They are mechanically tough and flame retardant. They withstand temperature tests where the temperature ranges from the cold bend at $-65^{\circ} \mathrm{C}$ to aging at $300^{\circ} \mathrm{C}$ over $7 \mathrm{~h}$. 
The National Aeronautics and Space Administration (NASA) reported that XL-ETFE does not meet the flammability criteria in $30 \%$ oxygen. Indeed, XL-ETFE can produce a substantial quantity of dense toxic smoke $(96 \%+$ density) when it burns. The Grumman Corporation banned it in 1982, and NASA followed suit in 1983 [7].

\subsubsection{Perfluoroalkoxy Polymer, PFA}

PFA is a copolymer of TFE and perfluoroalkyl vinyl ether, such as perfluorinated propyl vinyl ether (PPVE). The biggest difference between PTFE and PFA is that PFA can be melt-processed. PFA cannot withstand water absorption and weathering as PTFE. However, it is superior to PTFE in terms of salt spray resistance. PFA and PTFE exhibit similar dielectric constant and dissipation factor. PFA exhibits a significantly higher ( 3 to 4 times) dielectric strength. In service temperature ratings, both materials exhibit identical properties, but they differ in terms of cold flow (PFA better than PTFE) and folding endurance (PTFE better than PFA) properties [29].

\subsubsection{Fluorinated Ethylene Propylene, FEP}

Fluorinated ethylene propylene (FEP), also referred to as Teflon ${ }^{\circledR}$ FEP, is a copolymer of hexafluoropropylene (HFP) and TFE. The resistance values exhibited by FEP and PTFE toward caustic agents are comparable. However, FEP exhibits a significantly lower melting temperature compared to PTFE and PFA. FEP exhibits a similar dielectric constant as PTFE and PFA. In terms of mechanical strength, FEP cannot compete with PTFE regarding repetitive folding. However, FEP performs better than PTFE when it comes to coating applications involving exposure to detergents [30].

\subsubsection{Comparison of Properties}

Table 1 summarizes the key properties of commonly-used fluoroplastics that can be used for developing aeronautic wires. The information contained herein represents typical values obtained from literature/suppliers. The data obtained from literature reports have been used for comparison purposes only.

Table 1 Comparison of properties of PTFE, PFA, FEP, and ETFE.

\begin{tabular}{|c|c|c|c|c|c|}
\hline & Standard & $\begin{array}{l}\text { PTFE } \\
\left(\mathrm{CF}_{2} \mathrm{CF}_{2}\right)_{\mathrm{n}}\end{array}$ & $\begin{array}{l}\text { PFA } \\
\left(\mathrm{CF}_{2} \mathrm{CF}_{2}\right)_{\mathrm{n}^{-}} \\
\left(\mathrm{CF}_{2} \mathrm{CF}\left(\mathrm{OC}_{3} \mathrm{~F}_{7}\right)\right)_{\mathrm{m}}\end{array}$ & $\begin{array}{l}\text { FEP } \\
\left(\mathrm{CF}_{2} \mathrm{CF}_{2}\right)_{\mathrm{n}^{-}} \\
\left(\mathrm{CF}_{2} \mathrm{CF}\left(\mathrm{CF}_{3}\right)\right)_{\mathrm{m}}\end{array}$ & $\begin{array}{l}\text { ETFE } \\
\left(\mathrm{CF}_{2} \mathrm{CF}_{2}\right)_{\mathrm{n}^{-}} \\
\left(\mathrm{CH}_{2} \mathrm{CH}_{2}\right)_{\mathrm{m}}\end{array}$ \\
\hline $\begin{array}{l}\text { Max service, } \\
20,000 \mathrm{hrs}\left({ }^{\circ} \mathrm{C}\right)\end{array}$ & UL746 & 260 & 260 & 205 & 150 \\
\hline $\begin{array}{l}\text { Specific gravity } \\
\left(\mathrm{kg} \mathrm{dm}^{-3}\right)\end{array}$ & D792 & 2.15 & 2.15 & 2.15 & 1.70 \\
\hline $\begin{array}{l}\text { Dielectric Constant } \\
\left(10^{6} \mathrm{~Hz}\right)\end{array}$ & D1531 & 2.1 & 2.1 & 2.1 & 2.6 \\
\hline
\end{tabular}




\begin{tabular}{|c|c|c|c|c|c|}
\hline $\begin{array}{l}\text { Dissipation Factor } \\
\left(10^{6} \mathrm{~Hz}\right)\end{array}$ & D150 & $<0.0004$ & 0.0002 & 0.0002 & 0.007 \\
\hline $\begin{array}{l}\text { Dielectric Strength } \\
\left(\mathrm{kV} \mathrm{mm}^{-1}\right), 0.25 \\
\mathrm{~mm}\end{array}$ & D149 & $>20$ & 80 & 80 & 80 \\
\hline $\begin{array}{l}\text { Volume Resistivity } \\
\left(\Omega \mathrm{cm}^{-1}\right)\end{array}$ & D257 & $10^{18}$ & $10^{18}$ & $10^{18}$ & $10^{16}$ \\
\hline $\begin{array}{l}\text { Water absorption, } \\
24 \text { hrs (\%) }\end{array}$ & D570 & 0.01 & 0.03 & 0.01 & 0.03 \\
\hline $\begin{array}{l}\text { Limiting Oxygen } \\
\text { Index (\%) }\end{array}$ & D2863 & 95 & 95 & 95 & $30-36$ \\
\hline $\begin{array}{l}\text { Tensile strength at } \\
\text { break (MPa) }\end{array}$ & D1708 & $20-40$ & 27 & $25-30$ & 45 \\
\hline Elongation (\%) & $\begin{array}{l}\text { D1708, } \\
\text { D638 }\end{array}$ & $250-500$ & 300 & 300 & 200 \\
\hline $\begin{array}{l}\text { Izod Impact (notched), } \\
23^{\circ} \mathrm{C}\left(\mathrm{J} \mathrm{m}^{-1}\right)\end{array}$ & D256 & 160-190 & No break & No break & No break \\
\hline $\begin{array}{l}\text { Flexural Modulus } \\
\text { (MPa) }\end{array}$ & D790 & $450-600$ & 700 & $550-650$ & 1400 \\
\hline $\begin{array}{l}\text { Tensile Modulus } \\
\text { (MPa) }\end{array}$ & D638 & $350-550$ & $270-280$ & $350-500$ & $800-1300$ \\
\hline Melting Point $\left({ }^{\circ} \mathrm{C}\right)$ & D2236 & 327 & 305 & 270 & 260 \\
\hline Thermal & & & & & \\
\hline 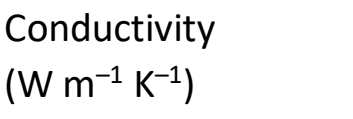 & C177 & 0.24 & 0.19 & 0.25 & 0.23 \\
\hline $\begin{array}{l}\text { CTE } 10^{-5} /{ }^{\circ} \mathrm{C} \\
\left(\text { rt- } 60{ }^{\circ} \mathrm{C}\right)\end{array}$ & D696 & $9-11$ & $11-13$ & $8-11$ & $9-11$ \\
\hline Arc resistance (s) & D495 & 300 & 180 & 300 & 75 \\
\hline $\begin{array}{l}\text { Dynamic coef. of } \\
\text { friction }\end{array}$ & D3028 & $0.05-0.15$ & $0.14-0.25$ & $0.14-0.25$ & $0.14-0.25$ \\
\hline
\end{tabular}

2.2.6 Wrapped vs. Extruded Fluoropolymers-Based Jackets 
An extruded wire was run through a die with the plastic tube hot-extruded around the wire as a cylinder. For a wrapped wire, the plastic in the form of a tape form was wrapped around the wire and seam-sealed. Tests were performed by the Lectromec Company. The results revealed that wire constructions with extruded insulation (AS22759/34, XL-ETFE) exhibited better performances than the tape wrapped constructions (AS22759/87 PTFE-Polyimide construction). AS22759 specification covers the fluoropolymer-insulated single conductor electrical wires made of $\mathrm{Sn}-, \mathrm{Ag}-$, or $\mathrm{Ni}$-coated conductors of $\mathrm{Cu}$ or $\mathrm{Cu}$-alloy. The fluoropolymer insulation of these wires can potentially be constructed with PTFE, FEP, PVDF, ETFE, or other fluoropolymer resins [31]. Tape wrapped constructions contain more voids; thus, facilitating the generation of partial discharges (Figure 5) [32].

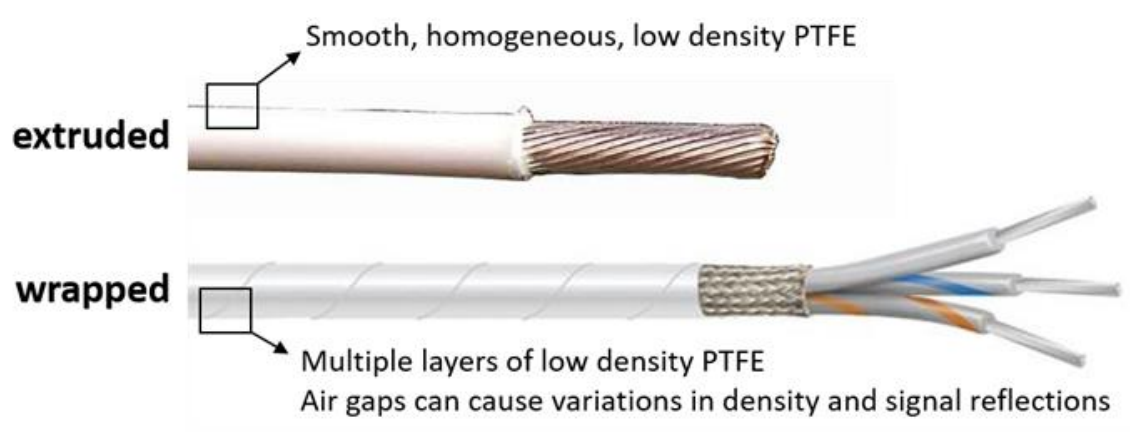

Figure 5 Wrapped vs. extruded PTFE-based jackets.

It is more appropriate to compare extruded versus tape-wrapped PTFE. In this juxtaposition, extruded PTFE exhibits the problems of ring-cracks and axial splits, according to the Druflon Company [33]. This Company manufactures PTFE Sleeves/Tubings following the "Tape-Wrapping Sintering" (TWS) method (Figure 6). Unsintered PTFE tapes of uniform thicknesses are wrapped around a mandrel and sintered. Several layers of tapes are fused into a homogenous one. Following this, the mandrel is removed, leaving behind the sleeve. The insulation is not extruded into the interstices of the wire strands. In addition, the molecular structure of Druflon-TWS PTFE prevents tears, which can be attributed to its biaxial orientation.

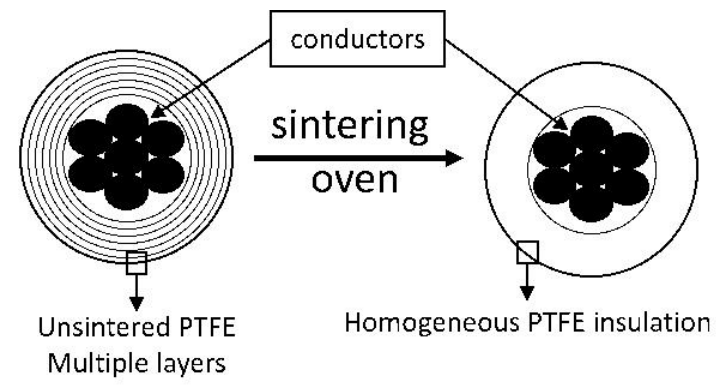

Figure 6 Tape-Wrapping-Sintering (TWS) method.

The TWS process is comparable to the process pioneered by W.L. Gore \& Associates [34]. Wilbert Lee Gore (1912-1986), employed in the period of 1953-57 by the DuPont Company, was conducting research in the basement of his home. Gore's son, Robert (still a sophomore in college at that time), suggested his father to take some unsintered tape of PTFE and feed the tapes in the nips of the 
calendar rolls, one on each side, and make a wiring strip instead of trying to control the feeding of the powder into the rolls. Wilbert Gore was surprised that the two pieces of extruded PTFE tape adhered tightly together and that the resulting assembly did not tear itself apart during the process of sintering, which required heating well above the PTFE crystalline melt temperature. Subsequent dielectric tests on the laminated ribbon cable assembly, conducted the next day, proved that this process produced an electrically sound cable.

Nowadays, for the development of next-generation wires, Gore aims to combine the best properties of the current solutions without: i) resorting to aromatic hydrocarbons (widely mistrusted because they are prone to arc tracking), and ii) increasing the thickness and weight. Based on future needs, Gore focuses on the following key attributes: i) voltage breakdown and endurance, ii) (dynamic) cut-through resistance, and iii) arc (wet and dry) resistance. The specifications are based on AS22759 (vide supra), although the ultimate performance target is JSWAG "enhanced" specs (JSWAG-Joint Services Wiring Action Group-a joint service forum providing advancements in safety, reliability, maintainability, and readiness of all Department of Defense aircraft by improving the electrical wire and interconnect systems (EWIS) and fiber optic cable systems) [35].

\subsubsection{A Commercially-Available High-Temperature Engineered Fluoropolymer}

In 2011, DuPont released a novel high-temperature melt-processable resin, referred to as the ECCtreme $^{\circledR}$ ECA (Figure 7) $[36,37]$.

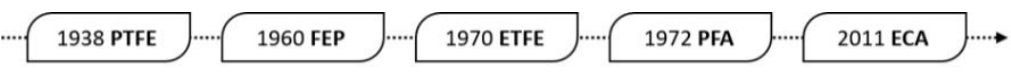

Figure 7 Chemours at the forefront of fluoropolymer innovation for over 75 years.

This resin can be operated above the long-standing upper-use limit of $260{ }^{\circ} \mathrm{C}$. The upper limit could be extended by $40{ }^{\circ} \mathrm{C}$. This particular feature was achieved following the process of epitaxial co-crystallization (ECC). This phenomenon is characterized by an increase in crystallinity via two pathways: i) spherulite growth within the crystal structure and ii) end-to-end coupling of the polymer chains. The resin can be easily processed into shapes, tubes, or wire coatings. The initial composition consists of a dry blend mixture of PFA and low molecular weight PTFE, referred to as the PTFE micropowder [38]. The PFA used can be a copolymer of TFE and perfluoropropoxyethylene (PPVE) with a PPVE content of $4.2 \mathrm{wt}$.\%. The end-groups of this PFA are primarily carboxylic acids. A small proportion of carbonyl fluorides are also present. The PTFE micropowder, for instance, Zonyl ${ }^{\circledR}$ fluoroadditive, is a powder with an average particle size of $12 \mu \mathrm{m}$. It is generally composed of at least 20 wt.\% of Zonyl ${ }^{\circledR}$. The two polymers are dry blended and then melt-mixed. The PFA and fluoroadditive constituents crystallize independently (two melting temperatures are observed). Heat aging of the solid-state mixture engenders the epitaxial co-crystallization, resulting in a single melting temperature.

Compared to the fully and partially fluorinated fluoropolymers, this resin demonstrates the following features [38]: a high combination of temperature and chemical resistance, superior abrasion resistance of PTFE, no degradation of tensile modulus properties after nearly two years of constant exposure to a temperature of $315{ }^{\circ} \mathrm{C}$, a dielectric constant similar to that exhibited by other melt-processable perfluoropolymers, and a dissipation factor lower than that of standard PFA. 
Of its electrical properties, $97 \%$ was retained after 14 months of heat exposure at $310{ }^{\circ} \mathrm{C}(10$ degrees above its upper use temperature). Improved gas permeation resistance (both carbon dioxide and oxygen), improved permeation resistance to concentrated $\mathrm{HCl}$, resistance to fuming sulfuric and nitric acids, bases, aggressive peroxides, antioxidants (as used in high-temperature oils), and methanol (as used in fuel) were observed. The parts molded from the resin were unaffected when exposed to high-pressure steam, a common enemy of many fluoropolymers. However, strong oxidizing acids, organic bases, and sulfonic acids (at high concentrations and near their boiling points) can potentially affect the properties of the resin.

The Rubadue Wire Company chose DuPont ECCtreme fluoroplastic resin due to its highperformance features [39]. ECA-coated wire materials exhibit enhanced performances when exposed to temperatures above $280{ }^{\circ} \mathrm{C}$. Their wires range from AWG (American Wire Gauge) 8 to AWG 30 fabricated with $27 \%$ nickel-plated copper conductor (solid or stranded) and are rated for $300{ }^{\circ} \mathrm{C}$, and $600 \mathrm{~V}$. The Zeus Company has also developed processes to extrude ECCtreme ${ }^{\circledR}$ ECA heat-insulated wires [40].

\section{Aircraft Environment vs. Wire Reliability}

Aircraft constraints are:

i) Electrical: Conductivity, attenuation, electromagnetic Interference (EMI)

ii) Mechanical: Vibration, abrasion

iii) Environmental: Temperature, contaminants

iv) Application-Specific: Lightest weight, smallest diameter, performance criteria

The two most important factors that should be considered during the development of aircraft applications are safety and weight. Operating costs are related to the weight of the aircraft. Thus wires must be electrically and mechanically robust. They should also not add significant mass to the aircraft. The ideal cable helps achieve maximum performance with the smallest size and lowest weight.

Cable shielding is also crucial as electromagnetic interference (EMI) is encountered. The development of composite materials for use in aircraft structures has modified the electrical characteristics of modern aircraft in terms of EMI. Hence, it is necessary to improve shielding at the cable bundle level to protect electronic systems.

Mechanical stress includes vibration, acceleration loads, and potential damage during installation and maintenance. Wire chafing can have a detrimental effect on wire reliability. This phenomenon is typically caused by wires rubbing against each other or their fixtures over time.

The aircraft environment exposes cables to contaminants such as deicing fluids, hydraulic fluids, cleaning solutions, and water. Such contaminations lead to arc tracking [4], "a phenomenon whereby an arc between 2 or more wires, on initiation, will sustain itself through a conductive path provided by the degradation of the insulation for a measurable length" [41]. The comparative tracking index (CTI) is commonly used to measure the arc tracking properties of insulation material (IEC 60112 [42], ASTM D368 [43]).

Wires must operate over a wide pressure range (e.g., the pressure is $3.3 \mathrm{psi}$ at $36,000 \mathrm{ft}$ and 11,3 psi at 7,000 ft). They are also exposed to extreme temperature fluctuations based on the proximity to hot zones on the aircraft. When polymers are exposed to high temperatures, close enough to $T_{\mathrm{m}}$ and beyond $T_{\mathrm{g}}$, polymer chains reorder, leading to shrinkage. When shrinkage exceeds the tensile 
strength, cracks appear. "Mandrel wrap tests" (MIL-W-22759) are the comprehensive tests for stress crack resistance of wires. Stress cracking can also be caused by environmental and mechanical stresses [44].

Miles of wires are present inside Aircraft harnesses (e.g., approximately 330 miles in the Airbus 380 and 140 miles weighing about 3,500 pounds in the Boeing 747) that are often hard to reach. The most frequent cause of electrical fires are: (i) wear because of aging and exposure to heat, (ii) tear resulting from mechanical stress, (iii) chemical contamination, and (iv) breaks in insulation leading to the exposure of metal conductors.

The electrification at the horizon is another constraint that should be considered as the boundaries of commonly-employed wires are significantly pushed. Hence, a new generation of insulating materials capable of handling higher continuous-use temperatures and voltage are on demand. As mentioned earlier, the operating voltages should be below 1000 VDC. Regarding the temperature, the typical operating temperature of the insulation material must range from $-70{ }^{\circ} \mathrm{C}$ to $+300{ }^{\circ} \mathrm{C}$ for a minimum of $90,000 \mathrm{~h}$. Hence, the low thermal conductivity of polymers presents a technological barrier, especially for high-temperature applications [45].

\section{Thermal Conductivity}

Improved thermal conductivity is required for heat dissipation to increase the lifespan of wires. Bulk polymers commonly exhibit low thermal conductivity $\left(0.1-0.5 \mathrm{~W} \mathrm{~m}^{-1} \mathrm{~K}^{-1}\right)$ because of the random alignment of amorphous domains that tends to localize the vibrational modes.

Over the last two decades, researchers have come to the following conclusions [45]:

(i) A high side-chain density lowers the thermal conductivity. Conversely, enhancing stretching and bending strength of polymer backbone bonds engenders a higher thermal conductivity.

(ii) The thermal conductivity is improved at low nanofiller concentration, but the aggregation of fillers may have the opposite effect when the concentration is further increased. However, if the filler concentration is increased further, the thermal conductivity can be improved because of the formation of heat transport networks (which can be attributed to the aggregation of fillers).

(iii) The intrinsic 3D network of 3D fillers such as carbon foam, graphene foam, and expanded graphite can help reduce the thermal conductivity without thermal contact resistance.

(iv) Double filler composites can potentially exhibit a higher thermal conductivity, which can be attributed to the bridging effect between both networks and a reduced inter-filler thermal resistance.

(v) The effect of cross-linking knots and hydrogen bonding is still not clearly understood. Further investigations are needed to understand the effect.

\section{Conclusions}

In the future, electrical systems will play an even more important role in determining the efficiencies of more electric aircraft. A new generation of insulating materials capable of handling higher continuous-use temperatures and voltages ( $300^{\circ} \mathrm{C}$ and $1000 \mathrm{VDC}$, respectively) needs to be developed. Polyimides such as Kapton ${ }^{\circledR}$ paired with fluoropolymers such as Teflon ${ }^{\circledR}$ PTFE are known to perform well in high-temperature environments (up to $260{ }^{\circ} \mathrm{C}$ ). Nevertheless, for the development of next-generation wires, influential companies are keen to combine the best properties of current solutions without resorting to aromatic hydrocarbons (mistrusted because 
they are prone to arc tracking). In 2011, Chemours reported the synthesis of a high-temperature melt-processable resin that surpasses the long-standing upper-use limit of $260{ }^{\circ} \mathrm{C}$. The upper limit was extended by $40{ }^{\circ} \mathrm{C}$. This resin thus appears as a great candidate for use in high-temperature environments. However, it has been understudied for use as wire materials. There is no doubt that fluoropolymers, especially fluoropolymers composites, will continue to be one of the leading insulation materials for high-performance wire applications. Chafing can exert a detrimental effect on wire reliability, and the addition of fillers can solve this problem. Similarly, the use of 3D fillers is an interesting way of enhancing the thermal conductivity of polymers.

\section{Author Contributions}

The author did all the research work of this study.

\section{Competing Interests}

The author has declared that no competing interests exist.

\section{References}

1. Howse M. All-electric aircraft. Power Eng. 2003; 17: 35-37.

2. Christou I, Nelms A, Cotton I, Husband M. Choice of optimal voltage for more electric aircraft wiring systems. IET Electr Syst Transp. 2011; 1: 24-30.

3. Madonna V, Giangrande $P$, Galea M. Electrical power generation in aircraft: Review, challenges, and opportunities. IET Electr Syst Transp. 2018; 4: 646-659.

4. Riba JR, Gómez-Pau Á, Moreno-Eguilaz M, Bogarra S. Arc tracking control in insulation systems for aeronautic applications: Challenges, opportunities, and research needs. Sensors. 2020; 20: 1654.

5. Drobny JG. Polymers for electricity and electronics: Materials, properties, and applications. New Jersey: John Wiley \& Sons; 2012.

6. Kurek J, Bernstein R, Turner N, Etheridge M, LaSalle G, McMahon R, et al. Aircraft wiring degradation study. Final report. Washington, DC: Air Traffic Organization Operations Planning Office of Aviation Research and Development; 2008; 20591.

7. Paterson A. Aircraft electrical wire types associated with aircraft electrical fires [Internet]. An Aviation $\quad 2007 . \quad$ Safety; Available from: http://www.vision.net.au/ apaterson/aviation/wire types.htm.

8. Ebnesajjad S. Introduction to fluoropolymers: Materials, technology, and applications. 1st ed. British: Elsevier; 2013.

9. Dhanumalayan E, Joshi GM. Performance properties and applications of polytetrafluoroethylene (PTFE) - a review. Adv Compos Hybrid Mater. 2018; 1: 247-268.

10. Deli G, Qunji X, Hongli W. Study of the wear of filled polytetrafluoroethylene. Wear. 1989; 134 : 283-295.

11. Blanchet TA, Kennedy FE. Sliding wear mechanism of polytetrafluoroethylene (PTFE) and PTFE composites. Wear. 1992; 153: 229-243.

12. Conte M, Igartua A. Study of PTFE composites tribological behavior. Wear. 2012; 296: 568-574. 
13. Lancaster JK. The effect of carbon fibre reinforcement on the friction and wear of polymers. J Phys D Appl Phys. 1968; 1: 549.

14. Tanaka K, Kawakami S. Effect of various fillers on the friction and wear of polytetrafluoroethylene-based composites. Wear. 1982; 79: 221-234.

15. Bhargava S, Blanchet TA. Unusually effective nanofiller a contradiction of microfiller-specific mechanisms of PTFE composite wear resistance? J Tribol. 2016; 138: 042001.

16. Ebnesajjad S. 16. Filled Fluoropolymer Compounds. In Fluoroplastics, Volume 1: Non-melt processible fluoropolymers-the definitive user's guide and data book. 2nd ed. Norwich, NY: William Andrew; 2014. pp.336-381.

17. Venkateswarlu G, Sharada R, Rao MB. Effect of fillers on Di-electric strength of PTFE based composites. Int J Sci Res Publ. 2015; 5: 560-568.

18. Wada Y. Valqua technology news [Internet]. Spring 2017, No. 32. Available from: http://www.valqua.co.jp/wp-content/uploads/pdf/technical/32e/vtn032e.pdf.

19. Makowiec ME, Blanchet TA. Improved wear resistance of nanotube-and other carbon-filled PTFE composites. Wear. 2017; 374: 77-85

20. Exceptional dimensional stability for precise tolerance control [Internet]. Mistubishi Chemical Advanced Materials. Available from: http://www.mcam.com/fr/industries/traitementchimique-petrole-et-gaz/fluorosintr-500.

21. Pasha BM, Budan DA, Basavarajappa S, Yadav SM, Nizamuddin BA. Studies on wear resistance of PTFE filled with glass and bronze particles based on Taguchi technique. J Thermoplast Compos Mater. 2013; 26: 243-259.

22. Bessede JL, Elkoun S, Stochmil C, Etienne S. Dielectric properties of PTFE-based composite insulating materials: Interfaces effects. Proceeding of the 2000 Annual Report Conference on Electrical Insulation and Dielectric Phenomena. 2000 October 15-18; Victoria, Canada. New York: Institute of Electrical and Electroics Engineers.

23. Aderikha VN, Krasnov AP, Shapovalov VA, Golub AS. Peculiarities of tribological behavior of lowfilled composites based on polytetrafluoroethylene (PTFE) and molybdenum disulfide. Wear. 2014; 320: 135-142.

24. Dhas DJ, Senthilnathan S, Manivannan G, Azhagesan N. Extensive investigation in wear behavior of alumina-PTFE composite for medical implant applications. Int J Compos Mater. 2017: 7; 115119.

25. Ekonol ${ }^{\circledR}$ polyester fillers for PTFE seals \& bearings [Internet]. Saint-Gobain Coating Solutions. Available from: http://www.coatingsolutions.saint-gobain.com/materials/ekonol-polyesterfillers-ptfe-seals-bearings.

26. Polyimide-filled polytetrafluoroethylene (SP191) [Internet]. BALSEAL Engineering Inc. Available from: http://www.balseal.com/wpcontent/uploads/2019/03/sp 191 material data sheetM 64.pdf.

27. Boddapati A. Measurement of fluoride generated from fluoropolymer wire insulations [Internet]. Washington, D. C.: NASA; 2011; GSFC.CPR.4758.2011. Available from: https://ntrs.nasa.gov/citations/20110015288.

28. Flexible cross - linked fluoropolymer [Internet]. Manchester, NH: Marmon Aerospace \& Defense. Available from: http://www.marmon-ad.com/aerospace/cross-linked-etfe. 
29. PTFE and PFA similarities and differences [Internet]. St. Louis, MO: Emerson Electric. Available from: http://www.emerson.com/documents/automation/white-paper-ptfe-pfa-similaritiesdifferences-rosemount-en-585104.pdf.

30. What it is Fluorinated Ethylene Propylene (FEP)? [Internet] Huizhou: Guanghai Material. Available from: http://www.gh-material.com/news/what-it-is-fluorinated-ethylene-propylenefep-5961495.html.

31. Wire, electrical, fluoropolymer-insulated, copper or copper alloy [Internet]. SAE International. Available from: http://www.sae.org/standards/content/as22759/.

32. Traskos M. High voltage impact the aircraft wiring system [Internet]. Chantilly, VA: Lectromec. Available from: http://www.lectromec.com/high-voltage-impact-the-aircraft-wiring-system.

33. PTFE insulated wires - advantages of TWS method [Internet]. Ghaziabad: Druflon. Available from: http://www.druflon.com/twswires.html.

34. The gore story [Internet]. Newark, DE: Gore. Available from: http://www.gore.com/about/thegore-story?view=our-history.

35. Joint Services wiring action group [Internet]. Patuxent River, MD: U.S. Navy. Available from: http://www.navair.navy.mil/jswag/.

36. Lahijani J. Melt-fabricable perfluoropolymers having improved heat aging property. Wilmington, DE: El du point de Nemours \& Company; 2014; US8648147B2.

37. Strabelli P. New melt-processable perfluoropolymer with upper use temperature of 300 degrees celsius. OTC Brasil. 2013.

38. ECCtreme ${ }^{\mathrm{TM}}$ ECA fluoropolymer resins [Internet]. Wilmington, DE: The Chemours Company. Available from: http://www.teflon.com/en/products/resins/eca-resins.

39. Rubaduewire. Greeley, CO: Rubadue Wire Company, Inc. Available from: http://dta0yqvfnusiq.cloudfront.net/rubad78253624/2018/09/rubadue-wire-catalog5ba3f734378f3.pdf.

40. Insulated Wire [Internet]. Zeus Industrial Products, Inc. Available from: http://www.zeusinc.com/products/insulated-wire/.

41. Sylvester J. Aerospace electrical cable arcing failure. Bremen, Germany: MBB/ERNO; 1991.

42. IEC. IEC 60112:2020 CMV Commented version. Method for the determination of the proof and the comparative tracking indices of solid insulating materials. Geneva, Switzerland: IEC Stand; 2009.

43. ASTM. ASTM D3638 - 12. Standard test method for comparative tracking index of electrical insulating materials. West Conshohocken, PA, USA: ASTM; 2012.

44. Baillie RL, Bednarczyk JJ, Mehta PM. PTFE resin selection for high performance wire and cable. Proceedings of 35th International Wire and Cable Symposium; 1986 November 18-20; Reno, Nevada. E.I. du Pont de Nemours \&Co., Inc.

45. Gong D, Xue Q, Wang H. Study of the wear of filled polytetrafluoroethylene. Wear. 1989; 134: 283-295. 


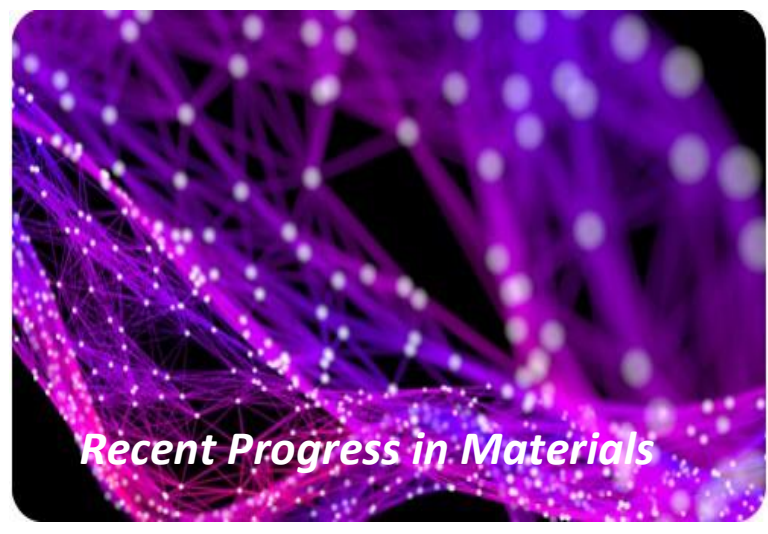

Enjoy Recent Progress in Materials by:

1. Submitting a manuscript

2. Joining in volunteer reviewer bank

3. Joining Editorial Board

4. Guest editing a special issue

For more details, please visit:

http://www.lidsen.com/journals/rpm 